\title{
Tai chi: physiological characteristics and beneficial effects on health
}

\author{
J X Li, Y Hong, K M Chan
}

\begin{abstract}
Objectives-To assess the characteristic effects of Tai Chi Chuan (TCC) exercise on metabolism and cardiorespiratory response, and to measure its effect on cardiorespiratory function, mental control, immune capacity, and the prevention of falls in elderly people.
\end{abstract}

Design-A review of controlled experimental studies and clinical trials designed with one of two aims: either to assess physiological responses during the performance of TCC or to assess the impact of this exercise on general health and fitness.

Main outcome measures-Metabolic rate, heart rate, blood pressure, ventilation, maximal oxygen uptake ( $\left.\dot{\mathrm{V}}_{2} \mathrm{MAx}\right)$, immune capacity, falls, and fall related factors.

Subjects-A total of 2216 men and women. Results-Under review were 31 original studies, published in Chinese or English journals, that met the criteria for inclusion. Most of the papers written in Chinese had not been introduced into the Western literature. Nine of these studies showed that TCC can be classified as moderate exercise, as its does not demand more than $55 \%$ of maximal oxygen intake. When this form of exercise and others conducted at equal intensity were compared, TCC showed a significantly lower ventilatory equivalent (VE/Vo $\mathrm{O}_{2} \mathrm{MAx}$ ). Evidence provided by cross sectional and longitudinal studies suggests that TCC exercise has beneficial effects on cardiorespiratory and musculoskeletal function, posture control capacity, and the reduction of falls experienced by the elderly.

Conclusions-TCC is a moderate intensity exercise that is beneficial to cardiorespiratory function, immune capacity, mental control, flexibility, and balance control; it improves muscle strength and reduces the risk of falls in the elderly. (Br F Sports Med 2001;35:148-156)

Keywords: Tai Chi Chuan; elderly; falls; cardiovascular; ventilation
In most of the English literature, Tai Chi Chuan (abbreviated to TCC, but expressed in the Chinese phonetic alphabet as Taijiquan) is described as a traditional Chinese form of exercise derived from martial arts folk traditions. The word "Chuan" means "boxing", but in some of the literature it has been omitted.

TCC developed to the point of formalisation in the late Ming (1368-1644) and early Qing (1644-1911) dynasties. To understand this set of systematic callisthenic exercises, one must first appreciate the origin and broad significance of the term "Tai Chi". The term first appeared in the books of "I Ching", and indicated the encompassing state of the universe before the creation of heaven and earth. Therefore, all TCC movement is considered circular. Within this circular movement are many concealed variations and changes: there is emptiness and fullness, strength and softness, movement forward and backward and stillness. TCC is used to seek serenity in action, and action in serenity. The emphasis is on the exercise of mind and consciousness. TCC movements are continuous from beginning to end, and from one posture to the next, in a completely integrated circle.

Many TCC schools, such as those of Chen, Yang, Sun, and Wu, developed over the centuries. However, in 1956 a meeting of masters convened by the Chinese National Council of Sports and Physical Education produced a "combined" style. This simplified 24 form TCC was designed to convey the most representative components of the traditional schools, and to make them easy to learn and practice in less time than usual. ${ }^{1}$ The government and various health, education, and sports related bodies have subsequently expended much effort to promote and spread the simplified form of TCC among the population in China, and it has been included in the compulsory teaching content of most colleges and universities. Today millions of Chinese practice TCC, and it has become one of the most popular forms of exercise or sport, especially among elderly people.

The practice of TCC was originally related to concerns about physical fitness and the capacity for self defence. However, over the centuries, it has become far more focused on the homoeostasis of the body's internal environment. The interaction between mind and 
body has long been seen as more important than the development of any martial arts skills. This very point was mentioned in Tai Chi Chuan classic" (Wang 1642), which was published in the Ming dynasty and, to our knowledge, was the first book about TCC.

The first scientific description of the effect of TCC on health has been traced by $\mathrm{Yu}^{2}$ to $\mathrm{Xu}$ Zhi-Yi's 1927 Chinese book, Preliminary explosion of Tai Chi Chuan. This book explained the beneficial impact of TCC on the physiology, psychology, and kinesiology of the human body. $\mathrm{Yu}^{2}$ also refers to another Chinese book, which was published in 1931 by Wu Tu-Nan and discussed the "scientificisation" of TCC. With the development of science and technology in China during the twentieth century, research on TCC has aroused increasing interest in a wide range of areas such as medicine, exercise science, physical education, and psychology.

During the past 20 years, TCC has also spread throughout Western countries, and its beneficial effects have stimulated the research interests of Western scientists. However, to our knowledge, the first paper in English that presented an experimental study of TCC was actually published in China during $1981 .^{3}$ Later that year, $\mathrm{Koh}^{4}$ published a paper that introduced TCC to international journals. $\mathrm{He}$ then published a self report about the effects of TCC exercise on health. ${ }^{5}$ In 1988, Xu and Fan published an English review paper about physiological studies of TCC in a book called China's sports medicine. ${ }^{6}$ TCC exercise and its impact on human health was gradually understood by the Western world. With the prevalence of ageing populations world wide and concomitant increases in expenditure on the relief of chronic disease and disability, interest in TCC has continued to grow. Published results from well controlled studies about the effects of TCC, particularly those focusing on the elderly, have added to the understanding of the characteristics of TCC movement and its impact on health.

Exercise has definite effects on the health of older people, but appropriate forms are scarce, as ageing is usually accompanied by a significant decline in organ function. It is well known that joint degeneration, poor eyesight and balance, and loss of stamina are universal in the elderly. Therefore, low velocity, low impact exercises in which interest is easily maintained are the most effective. Reports in the literature would suggest that TCC can provide all that is required by elderly people from exercise. In addition, it has the potential to reduce expenditure generated by poor health, because it facilitates a lifestyle that promotes wellbeing among people of all ages. However, before these broad observations can be endorsed, two relevant questions must be answered. What evidence actually exists to suggest that TCC affords any benefits? If such benefits do exist, then what are their underlying mechanisms? The purpose of this article is to review scientific studies in both Chinese and English on the physiological characteristics of this intriguing form of exercise, and their impact on participant health. Such a review should provide the basis of future studies.

\section{Characteristics of TCC}

METABOLIC RESPONSES

Numerous studies on metabolic responses during the performance of TCC have been reported in both Chinese and English. Chen and $\mathrm{Zhao}^{7}$ studied energy expenditure and the micro-circulation condition in the fingers of 30 TCC practitioners of 50-65 years of age. They had been practising TCC for between six months and 20 years, and were divided into three groups according to their style (Chen, Yang, or simplified 24 form TCC). Energy expenditure was measured in 10 subjects from each group during the performance of TCC, through the collection and analysis of exhaled air. Each subject was asked to perform TCC by using both the higher and lower positions of the centre of gravity. In the higher position, the knee angle was about $150^{\circ}$ in most of the movements with semisquat positions, whereas in the lower position this angle was around $120^{\circ}$. The results showed that the average time taken to practice Yang TCC was 17 minutes, whereas only six minutes were needed for Chen, and five minutes for the simplified 24 form TCC. However, the performance of Chen TCC demanded significantly higher energy expenditure than Yang or simplified 24 form TCC. Furthermore, practising TCC with lower position techniques required significantly more energy than practising TCC with higher position techniques. The mean (SD) oxygen uptakes for the higher and lower position techniques were $1.00(0.26) 1 / \mathrm{min}$ and $1.36(0.37)$ $1 / \mathrm{min}$ for Chen TCC, $0.55(0.13) 1 / \mathrm{min}$ and $0.77(0.11) \mathrm{l} / \mathrm{min}$ for Yang, and $0.58(0.14)$ $1 / \mathrm{min}$ and $0.77(0.18) 1 / \mathrm{min}$ for the simplified 24 form TCC.

Zhuo and his colleagues ${ }^{8}$ determined the oxygen cost and related metabolic variables in 11 healthy 24-35 year old men, who had practised the 108 form of Yang TCC regularly for three to eight years and possessed master TCC skills. The results showed that the average energy cost for the 108 form of Yang TCC was 4.1 metabolic equivalents (METs), which corresponded to a mean oxygen uptake of 1.03 $1 / \mathrm{min}$ or $14.5 \mathrm{ml} / \mathrm{kg} / \mathrm{min}$. Brown et al determined the metabolic variables in the 108 form of Yang TCC exercise. The "cloud hand" movement was selected for data collection, and the practitioners performed the complete set of Yang TCC. It was found that the mean energy cost at the 7 th, 14 th, and 21 st minutes after the beginning of the exercise, the times at which the "cloud hand" movements occurred, was 3.68 (1.58), 4.17 (1.44), and 4.27 (1.69) METs respectively, with a mean of 4.04 (1.56). Schneider and Leung ${ }^{10}$ found that the mean oxygen uptake while practising TCC was 1.19 (0.32) $1 / \mathrm{min}$, which equalled 4.6 (1.1) METs, in 10 male TCC practitioners who were 35.5 (3.9) years old and had regular experience of TCC for 6.8 (3.4) years. $\mathrm{Cao}^{11}$ measured energy expenditure in 10 TCC practitioners, seven of whom were men; mean (SD) age was 29.4 (8.6) years. Three of the subjects were 
Table 1 Summary of studies showing metabolic and cardiovascular responses during Tai Chi Chuan (TCC) exercise

\begin{tabular}{|c|c|c|c|c|c|c|}
\hline Reference & $\begin{array}{l}\text { Subject numbers } \\
\text { Average age (years) } \\
\text { TCC experience (years) }\end{array}$ & TCC style & $\mathrm{VO}_{2}(\mathrm{l} / \mathrm{min})$ & $\% \dot{V} O_{2} M A X$ & $M E T s$ & $\begin{array}{l}\text { Peak heart rate } \\
\text { (beats/min) }\end{array}$ \\
\hline$\overline{\text { Gong } e t ~} a l^{3}$ & $\begin{array}{l}\mathrm{N}=100 \\
\text { Age }=46-80 \\
\text { TCC }=0.5-30\end{array}$ & Simplified style & - & - & - & $104(14)$ \\
\hline Zhuo et $a l^{8}$ & $\begin{array}{l}\mathrm{N}=11 \\
\text { Age }=28.4 \\
\mathrm{TCC}=3-8\end{array}$ & Yang style & 1.03 & $<50 \%$ & 4.1 & 134 \\
\hline \multirow[t]{3}{*}{ Chen $e t a l^{7}$} & $\begin{array}{l}\mathrm{N}=10 \\
\text { Age }=50.9 \\
\mathrm{TCC}=0.5-5\end{array}$ & Chen style & $\begin{array}{l}1.00(0.26)(\mathrm{H}) \\
1.36(0.37)(\mathrm{L})\end{array}$ & - & $\begin{array}{l}4.8 \\
6.5\end{array}$ & $\begin{array}{l}107.2(15.3)(\mathrm{H}) \\
133.8(18.1)(\mathrm{L})\end{array}$ \\
\hline & $\begin{array}{l}\mathrm{N}=10 \\
\mathrm{Age}=65.6 \\
\mathrm{TCC}=2-10\end{array}$ & Yang style & $\begin{array}{l}0.55(0.13)(\mathrm{H}) \\
0.77(0.11)(\mathrm{L})\end{array}$ & & $\begin{array}{l}2.5 \\
3.5\end{array}$ & $\begin{array}{l}101.1(15.9)(\mathrm{H}) \\
115.8(20.0)(\mathrm{L})\end{array}$ \\
\hline & $\begin{array}{l}\mathrm{N}=10 \\
\text { Age }=60.0 \\
\text { TCC }=0.5-40\end{array}$ & Simplified form & $\begin{array}{l}0.58(0.14)(\mathrm{H}) \\
0.77(0.18)(\mathrm{L})\end{array}$ & & $\begin{array}{l}2.6 \\
3.5\end{array}$ & $\begin{array}{l}92.0(10.2)(\mathrm{H}) \\
107.7(13.5)(\mathrm{L})\end{array}$ \\
\hline Brown et al $l^{9}$ & $\begin{array}{l}\mathrm{N}=6(\mathrm{M}) \\
\text { Age }=34.3 \\
\mathrm{TCC}=8.3\end{array}$ & Yang style & $1.07(0.41)$ & - & $\begin{array}{l}4.04 \\
(1.56)\end{array}$ & $113.80(14.45)$ \\
\hline $\mathrm{Cao}^{11}$ & $\begin{array}{l}\mathrm{N}=10 \\
\text { Age }=29.4 \\
\text { TCC }=2-15\end{array}$ & Yang style & $0.708(0.206)$ & & $\begin{array}{l}2.87 \\
(0.88)\end{array}$ & $107.62(10.31)$ \\
\hline Schneider et $a l^{10}$ & $\begin{array}{l}\mathrm{N}=10 \\
\text { Age }=35.5 \\
\mathrm{TCC}=6.8\end{array}$ & - & $1.19(0.32)$ & $36.4(6.5)$ & $4.60(1.1)$ & $116(22)$ \\
\hline Lai $e t a l^{7}$ & $\begin{array}{l}\mathrm{N}=90 \\
\text { Age }=57\end{array}$ & Yang style & & & & $\begin{array}{l}130(14)(\mathrm{M}) \\
127(13)(\mathrm{F})\end{array}$ \\
\hline Lai $e t a l^{12}$ & $\begin{array}{l}N=84 \\
\text { Age }=50-64\end{array}$ & Yang style & - & - & - & $\begin{array}{l}128(\mathrm{M}) \\
122(\mathrm{~F})\end{array}$ \\
\hline Liu et $\mathrm{al}^{13}$ & $\begin{array}{l}\mathrm{N}=12 \\
\text { Age }=68.67 \\
\text { TCC }=10.6\end{array}$ & Simplified style & - & - & - & $\begin{array}{l}109.90(14.13)(\mathrm{a}) \\
110.00(12.27)(\mathrm{b}) \\
113.36(13.68)(\mathrm{c})\end{array}$ \\
\hline
\end{tabular}

Values are mean (SD).

M, male; F, female; H, high posture; $\mathrm{L}$, low posture; $a$, one set practised; $b$, two sets practised consecutively; c, three sets practised consecutively.

masters. Maximal oxygen uptake for all subjects was measured on a treadmill using Bruce's protocol. Oxygen uptake during performance of the 108 form of Yang TCC was measured by analysis of expired air. The results showed that the mean oxygen uptake while performing TCC was $0.708(0.206) 1 / \mathrm{min}$ (10.33 (3.2) $\mathrm{ml} / \mathrm{kg} / \mathrm{min})$, which equalled 2.87 (0.88) METs, or $24.74 \%$ of the mean maximal oxygen uptake ( $\left.\mathrm{V}_{2} \mathrm{MAX}\right)$ of the subjects. The mean heart rate of the subjects during practice was $55.66 \%$ of the mean maximal heart rate.

Table 1 summarises the studies that investigated metabolic and cardiovascular responses during TCC exercise. Oxygen uptake as measured by Chen and $\mathrm{Zhao}^{7}$ and $\mathrm{Cao}^{11}$ was lower than that measured by Zhuo et al. ${ }^{8}$, Brown ${ }^{9}$, and Schneider and Leung. ${ }^{10}$ Possible reasons for this difference may be the different testing procedures used, variations in the age of subjects, and their skill levels. Indeed, $\mathrm{Cao}^{11}$ stated that the three TCC masters in his study showed significantly higher oxygen uptake than the other subjects. On the basis of results obtained from published studies, the energy expended performing any form of TCC was about 4 METs.

\section{CARDIOVASCULAR RESPONSES}

Cardiovascular responses to TCC exercise have been reported in a variety of publications. As indicated above, the first paper in English was published during 1981, by Gong et al. ${ }^{3} \mathrm{~A}$ total of 100 healthy regular TCC practitioners, including 54 men and 46 women aged 46-80 years, participated in this study. The TCC experience of these participants varied from six months to 30 years. The changes in heart rate, blood pressure, and electrocardiogram (ECG) signals during performance of simplified 24 form TCC were examined by a telemetry monitoring system for 20 minutes. The results showed that the mean heart rate was 74 (10) beats/min before exercise, rose to 92 (16) beats/min after two minutes of exercise, and then stabilised at $95-98$ beats/min throughout the exercise. The mean peak heart rate was 104 (14) beats/min, and the mean maximal increase in the heart rate was 30 beats/min at $12-14$ minutes of exercise. When the subjects were divided into three groups according to their years of TCC experience, age, and resting heart rate before exercise, there was no significant difference in the changes in heart rate among the groups. Neither blood pressure nor ECG signals showed appreciable change before or after TCC exercise. Zhuo et $a l^{8}$ reported that the mean peak heart rate during TCC exercise was 134 beats $/ \mathrm{min}$. Similar results have been reported by Chen and Zhao, ${ }^{7}$ Brown et al, ${ }^{9}$ Schneider and Leung, ${ }^{10}$ Cao, ${ }^{11}$ Lai et al,,${ }^{12}$ and Liu et $a .^{13}$ The range of heart rate responses was $92-128$ beats $/ \mathrm{min}$. As table 1 indicates, TCC exercise as measured in these studies resulted in heart rate responses that were less than $60 \%$ of the individual maximum, at an exercise intensity that did not exceed $55 \%$ of the individual maximum oxygen uptake. TCC is thus characterised as a moderate form of exercise. 
Table 2 Summary of studies measuring the effects of Tai Chi Chuan (TCC) exercise on posture control

\begin{tabular}{|c|c|c|c|}
\hline Reference & $\begin{array}{l}\text { Subject numbers } \\
\text { Average age (years) }\end{array}$ & Design and measurements & Results \\
\hline Tse $e t a l^{14}$ & $\begin{array}{l}\mathrm{N}=9(\mathrm{TCC}) \\
\mathrm{N}=9 \text { (Con) } \\
\text { Age }=65-86\end{array}$ & $\begin{array}{l}\text { Cross sectional study } \\
\text { Single leg stance with both the eyes open and closed forms } \\
\text { Heel to toe walking with eyes open }\end{array}$ & $\begin{array}{l}\text { TCC group had significantly better posture control } \\
\text { capacity with vision. }\end{array}$ \\
\hline Schaller ${ }^{17}$ & $\begin{array}{l}\mathrm{N}=24(\mathrm{TCC}) \\
\mathrm{N}=22(\mathrm{Con}) \\
\text { Age }=70\end{array}$ & $\begin{array}{l}10 \text { week IN } \\
\text { Single leg stance with both the eyes open and closed forms } \\
\text { Sit and reach test }\end{array}$ & $\begin{array}{l}\text { Significantly improved balance capacity with vision, but } \\
\text { flexibility did not change. }\end{array}$ \\
\hline Wolf $e t a l^{18}$ & $\begin{array}{l}\mathrm{N}=72(\mathrm{TCC}) \\
\mathrm{N}=64(\mathrm{BT}) \\
\mathrm{N}=64(\text { Con }) \\
\text { Age }=76.2\end{array}$ & $\begin{array}{l}\text { (15 week IN \& } 4 \text { month follow up) } \\
\text { Isometric contractions about the hip, knee, or ankle } \\
\text { Grip strength } \\
\text { Fear of falling questionnaire }\end{array}$ & $\begin{array}{l}\text { Fear of falling was reduced after the TCC intervention, } \\
\text { when compared with the Education group. }\end{array}$ \\
\hline Wolfson $e t a l^{1}$ & $\begin{array}{l}N=110 \\
\text { Age }=80\end{array}$ & $\begin{array}{l}6 \text { month IN } \\
\text { Loss of balance during sensory organisation testing, single } \\
\text { stance time, voluntary limits of stability, isokinetic torque of } \\
\text { eight lower extremity movements, gait velocity }\end{array}$ & $\begin{array}{l}\text { TCC training has the effect of maintaining the significant } \\
\text { balance and strength gains. }\end{array}$ \\
\hline Shih $^{20}$ & $\begin{array}{l}\mathrm{N}=11 \\
\text { Age }=30.8\end{array}$ & $\begin{array}{l}16 \text { week IN } \\
\text { Velocity of sway in anterior and posterior in static and dynamic } \\
\text { conditions }\end{array}$ & $\begin{array}{l}\text { Significantly decreased the average velocity of sway in } \\
\text { dynamic conditions, but not in static conditions. }\end{array}$ \\
\hline Jacobson et $a l^{19}$ & $\begin{array}{l}\mathrm{N}=12(\mathrm{TCC}) \\
\mathrm{N}=12(\mathrm{Con}) \\
\text { Age }=30.4\end{array}$ & $\begin{array}{l}12 \text { week IN } \\
\text { Isometric muscle strength at } 90^{\circ} \text {, lateral body stability, } \\
\text { kinaesthetic sense in the glenohumeral joint at } 30^{\circ}, 45^{\circ} \text {, and } 60^{\circ}\end{array}$ & $\begin{array}{l}\text { Lateral stability, kinaesthetic sense at } 60^{\circ} \text {, and strength of } \\
\text { the knee extensor were significantly improved }\end{array}$ \\
\hline Hong et $a l^{16}$ & $\begin{array}{l}\mathrm{N}=28(\mathrm{TCC}) \\
\text { Age }=67 \\
\mathrm{~N}=30(\text { Con }) \\
\text { Age }=66.2\end{array}$ & $\begin{array}{l}\text { Cross sectional study } \\
\text { Single limb stance with the eyes open and eyes closed forms } \\
\text { Sit and reach test }\end{array}$ & $\begin{array}{l}\text { Long term TCC practice can significantly improve balance } \\
\text { capacity with and without vision, and flexibility }\end{array}$ \\
\hline
\end{tabular}

IN, Intervention; Con, control; BT, balance training.

\section{VENTILATORY RESPONSES}

Slow, deep, and diaphragmatic breathing, and an integration of body movement and breathing action are emphasised during the practice of TCC. The characteristics of breathing during TCC exercise have been shown by several experimental studies. Zhuo et $a l^{p}$ determined the respiratory frequency, ventilation $(\dot{\mathrm{V}} \mathrm{E})$, oxygen uptake $\left(\dot{\mathrm{V}}_{2}\right)$ and ventilation equivalent $\left(\dot{\mathrm{V}} / \dot{\mathrm{V}}_{\mathrm{O}_{2}}\right)$ during the performance of Yang TCC in 11 experienced practitioners. The results showed that the respiratory minute volume was relatively low when compared with the energy expenditure, which resulted in a lower ventilatory equivalent $(23.6(2.6))$. The mean respiratory frequency was 23.2 breaths per minute. In the study of Brown et $a l,{ }^{9} \mathrm{~V}_{2}$, ventilatory frequency (Vf), ventilatory equivalent $\left(\dot{\mathrm{V}}_{\mathrm{E}} / \dot{\mathrm{V}}_{\mathrm{O}}\right)$, and the ratio of dead space ventilation to tidal volume (VD/VT) were measured during the performance of the Yang TCC "cloud hand" movement. The data were then compared with the same measures when the subjects performed a submaximal cycle ergometry test at an oxygen consumption level equivalent to the mean $\dot{\mathrm{V}}_{2}$ in TCC. Significantly lower ventilatory frequency $(11.3 v 15.7$ breaths per minute), ventilatory equivalent (23.47 $v 27.41)$, and ratio of dead space ventilation to tidal volume $(20 \%: 27 \%)$ were found in TCC than in the cycle ergometry test. The percentage of minute ventilation used for alveolar ventilation was significantly higher during TCC than during cycle ergometry (81.1\% compared with $73.1 \%)$. The considerably lower respiratory frequency found in the study of Brown et al than in that of Zhou et al may be due to the difference in data collection. In the latter study, the physiological measurements were carried out through the whole period of TCC practice, whereas the data in the former were only collected during the "cloud hand" movement. Schneider and Leung $^{10}$ compared Wing Chun exercise and
TCC, and found that the minute ventilation for both Wing Chun and TCC exercises was relatively low when compared with the energy expenditure, which resulted in a lower ventilatory equivalent for oxygen uptake $\left(\dot{\mathrm{V}} \mathrm{E} / \dot{\mathrm{V}}_{2}\right)$. The mean $\dot{\mathrm{VE}} / \dot{\mathrm{V}}_{2}$ value for Wing Chun and TCC was 24.2 and 21.7 respectively, and they were similar to that reported by Zhuo et al (23.6) and Brown et $a l^{9}$ (23.47). These facts showed that the slow deep diaphragmatic breathing performed in TCC exercise was more efficient than that of cycling or Wing Chun when the intensity of each exercise was equivalent.

\section{Beneficial effects of TCC on health and fitness}

BALANCE, STABILITY, AND STRENGTH

TCC exercise demands precise joint movement, stability, and balance. Performing TCC depends on either double stance weightbearing or single stance weight-bearing manoeuvres, which further require the pivoting of the whole body or the twisting of the trunk. In performing TCC, the roles of the muscles continually change between those of stabilisers and movers, weight-bearers and non-weightbearers, and between contraction and relaxation. It has been suggested that the practice of TCC may increase the repertoire of motor programs stored in the brain ${ }^{14}$, and therefore serve to train the various balance systems to promote greater steadiness. Numerous studies on the impact of TCC exercise on balance, muscle strength, and flexibility have shown its beneficial effects, and table 2 summarises the experimental evidence.

Cross sectional studies have provided positive evidence that TCC has beneficial effects on balance and flexibility. Tse and Bailey ${ }^{14}$ reported that TCC practitioners were significantly better at performing right and left single leg stances with their eyes open and heel to toe walking than non-practitioners. However, this 
was not the case for single leg stances with eyes closed. Lan et $a l^{15}$ found that long term TCC practitioners showed better scores in the stand and reach test. Hong et $a l^{16}$ supported the findings of Lan et al by reporting that elderly long term (13.2 years) TCC practitioners performed better in tests of the single leg stance with eyes closed (right and left), total body rotation (right and left), knee extension, and ankle plantar flexion than the control group. This suggested that elderly people who exercise by using TCC long term and regularly can improve their balance capacity with and without the help of vision.

Besides the cross sectional studies, a number of TCC intervention studies of balance capacity and muscle strength in elderly people have been conducted. Schaller ${ }^{17}$ found that a 10 week course of an easy to learn westernised form of TCC resulted in significant improvements to the scores of single leg stances with eyes open, but not in those with eyes closed. Moreover, the scores of the sit and reach test for TCC practitioners did not improve. Wolf et $a l^{18}$ showed, with a large sample size, that a moderate TCC intervention could impact favourably on some biomedical and psychosocial indices of frailty. The results indicated that TCC participants substantially reduced their risk of multiple falls by as much as $47.5 \%$, in addition to other positive influences such as increases in hand grip strength and increased ambulating speed. Fear of falling was also reduced in the TCC group when compared with the non-exercise group. Jacobson et $a l^{19}$ reported significantly better balance control (tilting board test), strength of knee extension (maximal voluntary extension test), and kinaesthetic sense (glenohumeral media rotation at $90^{\circ}$ ) in adult TCC participants than the sedentary control group after a 12 week TCC intervention. Shih ${ }^{20}$ reported the average velocity of sway in his study of a 16 week TCC intervention, and stated that TCC exercise resulted in substantial reductions in anteroposterior sway velocities.

The beneficial effects of low intensity TCC exercise on the maintenance of gains in the balance and strength of older adults has also been shown by Wolfson et al. ${ }^{21}$ TCC intervention has helped alleviate joint pain and has increased strength, flexibility, and balance in older patients with osteoarthritis ${ }^{22}$ and rheumatoid arthritis. ${ }^{2324}$ TCC exercise has also had therapeutic effects on the range of motion in the upper extremities and the prevention of further deterioration.

\section{CARDIORESPIRATORY FUNCTION}

There is much evidence from clinical trials and exercise intervention for the beneficial effects of TCC exercise on cardiorespiratory function in both healthy people and patients with chronic diseases. The earliest scientific study of the effect of long term TCC practice on health was published in China in $1959 .^{25}$ The Beijing Medical University Institute of Sports Medicine examined cardiorespiratory function in 31 elderly people who had practised TCC for 40 years by using one minute step tests. The test was conducted on a $40 \mathrm{~cm}$ high bench, with a stepping rate of $15 \mathrm{steps} / \mathrm{min}$ for one minute. All but one of the TCC practitioners completed the test smoothly, but many more in the control group failed to finish. $\mathrm{Qu}^{26}$ reported the beneficial effects of TCC exercise on blood pressure in Chinese practitioners. He found that, in older Chinese TCC practitioners, there was a reduction in resting systolic blood pressure to $134 \mathrm{~mm} \mathrm{Hg}$ compared with a sedentary group $(154 \mathrm{~mm} \mathrm{Hg})$. Lai and coworkers ${ }^{27}$ examined the beneficial effects of TCC exercise on cardiorespiratory function. The results showed that at the maximal exercise level, the oxygen uptake $\left(\mathrm{VO}_{2}\right), \mathrm{O}_{2}$ pulse, and work rate of TCC practitioners were significantly higher than the respective values of sedentary subjects $(\mathrm{p}<0.01)$. At the ventilatory threshold, the TCC practitioners also showed a higher $\mathrm{VO}_{2}, \mathrm{O}_{2}$ pulse, and work rate $(p<0.05)$. Zhang ${ }^{28}$ examined the effect of one year of TCC exercise on cardiac function and working capacity in 11 healthy older people, who were matched by age and body mass with another 12 serving as a control group. The TCC training programme was of 30 minutes duration, five times a week. Measurements were conducted before and after the TCC programme. All cardiovascular measurements were taken in a resting supine position. The subjects were then asked to pedal for two minutes at $60 \mathrm{rpm}$ with zero resistance for warm up, and subsequently with a work rate increase of $15 \mathrm{~W} / \mathrm{min}$ until their heart rate reached 130 beats/min (PWC130 test). During the testing, heart rate was continuously monitored. Blood pressure and systolic time interval were examined at one, two, and three minutes after the PWC130 test. The results showed that one year of TCC exercise significantly improved working capacity. Cardiac function did not show any significant difference between the TCC and control group at rest. However, three minutes after the PWC130 test, TCC practitioners showed significantly better scores in the systolic time intervals, left ventricular ejection time, and time of QRST than the sedentary control group.

Similar findings were obtained during a two year longitudinal study, conducted by Lai et $a l,{ }^{12}$ which examined trends of cardiorespiratory function among older TCC practitioners and sedentary subjects. Practitioners practised TCC 5 (1.1) times a week, and each session included 20 minutes of warm up, 24 minutes of TCC training, and 10 minutes of cool down. The cardiorespiratory function $\left(\dot{\mathrm{V}}_{2} \mathrm{MAX}\right)$ in each subject was measured in the initial exercise test and two years later to determine the rate of decline of cardiorespiratory function. In the TCC group, there was a $2.8 \%$ decrease in $\dot{\mathrm{V}}_{2} \mathrm{MAX}$ in men and a $2.9 \%$ decrease in women. In contrast, the $\dot{\mathrm{V}}_{2} \mathrm{MAX}$ of the control group declined by $6.6 \%$ in men and $7.4 \%$ in women, showing that the regular practice of TCC may delay the decline in cardiorespiratory function in older adults.

In 1996, four studies on effects of TCC on cardiorespiratory function were published. ${ }^{151829}$ Lan et $a l^{15}$ reported a cross 
Table 3 Summary of studies on the impact of Tai Chi chuan (TCC) exercise on cardiorespiratory function

\begin{tabular}{|c|c|c|c|}
\hline Reference & $\begin{array}{l}\text { Subject numbers } \\
\text { Average age (years) }\end{array}$ & Design and measurements & Results \\
\hline BMUISM $^{25}$ & $\begin{array}{l}N=31 \\
\text { Age }=50-89\end{array}$ & 1 min step test, ECG, blood pressure & $\begin{array}{l}\text { TCC practitioners showed significantly better cardiac } \\
\text { function and lower blood pressure. }\end{array}$ \\
\hline Zhang $^{28}$ & $\begin{array}{l}\mathrm{N}=11(\mathrm{TCC}) \\
\text { Age }=61.33 \\
\mathrm{~N}=12(\mathrm{Con}) \\
\text { Age }=60.41\end{array}$ & $\begin{array}{l}1 \text { year IN } \\
\text { Working capacity }\left(\mathrm{PWC}_{130}\right) \text {, cardiac function, and } \\
\text { haemodynamics }\end{array}$ & $\begin{array}{l}\text { TCC group showed significantly better working power, } \\
\text { cardiac function, and blood dynamics. }\end{array}$ \\
\hline Lai et $a l^{12}$ & $\begin{array}{l}\mathrm{N}=84(\mathrm{TCC}) \\
\mathrm{N}=39 \text { (Con) } \\
\text { Age }=64\end{array}$ & $\begin{array}{l}2 \text { year IN } \\
\text { Cardiorespiratory function }\end{array}$ & $\begin{array}{l}\text { Regular practice TCC may delay the decline of } \\
\text { cardiorespiratory function in older adults. }\end{array}$ \\
\hline Channer et al ${ }^{9}$ & $\begin{array}{l}\mathrm{N}=38(\mathrm{TCC}) \\
\mathrm{N}=41 \text { (aerobic) } \\
\mathrm{N}=47 \text { (Con) } \\
\text { Age }=56\end{array}$ & $\begin{array}{l}8 \text { week IN } \\
\text { Blood pressure }\end{array}$ & $\begin{array}{l}\text { There was a negative trend in diastolic blood pressure in } \\
\text { the TCC group. Significant trends in systolic blood } \\
\text { pressure were found in the TCC and aerobic groups. }\end{array}$ \\
\hline Lan $e t a l^{15}$ & $\begin{array}{l}\mathrm{N}=41(\mathrm{TCC}) \\
\mathrm{N}=35(\mathrm{Con}) \\
\text { Age }=69.3\end{array}$ & $\begin{array}{l}\text { Cross sectional study } \\
\text { Cardiorespiratory function }\end{array}$ & $\begin{array}{l}\text { TCC practitioners have higher peak oxygen uptake, and } \\
\text { higher oxygen uptake at the ventilatory threshold. }\end{array}$ \\
\hline Schaller ${ }^{17}$ & $\begin{array}{l}\mathrm{N}=24(\mathrm{TCC}) \\
\mathrm{N}=22(\mathrm{Con}) \\
\text { Age }=70\end{array}$ & $\begin{array}{l}10 \text { week IN } \\
\text { Blood pressure }\end{array}$ & $\begin{array}{l}\text { TCC intervention did not change the systolic and diastolic } \\
\text { blood pressure. }\end{array}$ \\
\hline Wolf $e t a l^{18}$ & $\begin{array}{l}\mathrm{N}=72(\mathrm{TCC}) \\
\mathrm{N}=64(\mathrm{BT}) \\
\mathrm{N}=64 \text { (Education) } \\
\text { Age }=76.2\end{array}$ & $\begin{array}{l}15 \text { week IN and } 4 \text { month follow up } \\
\text { Cardiovascular endurance (12 minutes walk with } \\
\text { recorded heart rate and blood pressure) }\end{array}$ & $\begin{array}{l}\text { TCC training significantly improves cardiovascular } \\
\text { endurance. }\end{array}$ \\
\hline Young et $a l^{40}$ & $\begin{array}{l}N=62(\text { TCC or aerobic }) \\
\text { Age } \geqslant 60\end{array}$ & $\begin{array}{l}12 \text { week IN } \\
\text { Blood pressure }\end{array}$ & $\begin{array}{l}\text { TCC programme of light activity can decrease blood } \\
\text { pressure in previously sedentary adults. }\end{array}$ \\
\hline Lan $e t a l^{30}$ & $\begin{array}{l}\mathrm{N}=9(\mathrm{TCC}) \\
\mathrm{N}=11 \text { (Control) }\end{array}$ & $\begin{array}{l}1 \text { year IN } \\
\text { Cardiorespiratory function (peak oxygen uptake and } \\
\text { peak work rate) }\end{array}$ & $\begin{array}{l}\text { TCC exercise can enhance cardiorespiratory function in } \\
\text { patients who have experienced coronary artery bypass } \\
\text { surgery }\end{array}$ \\
\hline
\end{tabular}

IN, Intervention; BT, balance training.

sectional study which examined the cardiorespiratory function among long term TCC practitioners and sedentary subjects. Breath by breath measurement of $\mathrm{O}_{2}$ during the incremental exercise of leg cycling was used to examine the cardiorespiratory function in both long term regular TCC practitioners and sedentary geriatric subjects. The results showed that TCC practitioners, both men and women, had higher peak oxygen uptake than their sedentary counterparts. The TCC group also showed higher oxygen uptake at the ventilatory threshold. Wolf et $a l^{18}$ performed a prospective, randomised, controlled clinical trial with three groups: TCC practising, balance training, and education. The subjects in the TCC group were encouraged to practice TCC for at least 15 minutes twice a day. The 108 form of Yang TCC was reconstructed into a 10 form version that could be completed during a 15 week session. Blood pressure was examined in all subjects before and after a 12 minute walk on the start date and completion date of the TCC programme. Lower blood pressure was found in the TCC group before and after the 12 minute walk, but not in the balance training and education groups. However, Schaller ${ }^{17}$ found that such beneficial effects could not be detected after short term TCC practice. In this study, 24 elderly people participated in a 10 week programme of TCC exercise. They attended a 60 minute session each week and were asked to practice at home at least three times a week. The results showed that the practice of TCC for 10 weeks could improve the balance capacity with the help of vision, but did not lower blood pressure.

The therapeutic effects of TCC on patients with chronic cardiovascular disease have been reported by Lan et $a l,{ }^{30}$ who evaluated the training effect of a one year TCC programme for low risk patients with coronary artery bypass surgery after a postoperative outpatient, phase II, cardiac rehabilitation programme. Twenty subjects practised classical Yang TCC with an exercise intensity of $48-57 \%$ heart rate range. The nine men in the control group were instructed to undertake a home based self adjusted exercise programme with an intensity similar to that of phase II cardiac rehabilitation. Subjects in the TCC group practised 3.8 (1.5) times a week, in contrast with 1.7 (1.1) times a week for the control group. After one year of intervention, the $\dot{\mathrm{V}}_{2} \mathrm{MAX}$ of the TCC group increased $10.3 \%$ and the peak work rate increased $11.9 \%$. In contrast, the control group showed a slight decrease in $\dot{\mathrm{V}}_{2} \mathrm{MAX}$ and peak work rate.

Table 3 summarises the relevant studies. These studies show that the regular practice of TCC (over 15 weeks at 15 minutes twice a day) can produce beneficial effects in elderly people, by either improving cardiorespiratory function or delaying its decline. Moreover, patients with low risk chronic cardiovascular disease may enhance their cardiorespiratory function through TCC exercise.

\section{MENTAL CONTROL}

Tai Chi philosophy recognises that mental attitude can cause physiological change, which in turn affects the quality of movement. Mental stress is thought to make movement quick, tight, and erratic, which is quite the opposite of the graceful and flowing movement required in TCC practice. Moreover, the practice of TCC requires a combination of deep diaphragmatic breathing and relaxation with slow gentle movements. Thus TCC should have the effect of bestowing mental control ${ }^{5}$ on the practitioner. Jin has published two studies on the 
impact of TCC exercise intervention on mood and mental and emotional stress. His first study ${ }^{31}$ examined changes in psychological and physiological functioning after participation in TCC by 33 beginners and 33 practitioners. $\mathrm{He}$ found that the practice of TCC raised heart rates, increased noradrenaline (norepinephrine) excretion in urine, and decreased salivary cortisol concentration. Relative to baseline levels, subjects reported decreases in tension, depression, anger, fatigue, confusion, and anxiety. They felt more vigorous and in general had less total mood disturbance. Three years later, $\mathrm{Jin}^{32}$ examined the efficacy of TCC, brisk walking, meditation, and reading in reducing mental and emotional stress. Difficult mental tests were undertaken, and a stressful film was used to produce emotional disturbance, after which TCC and the other treatments were applied. The study showed that, in general, the stress reduction effect of TCC was characterised as that of moderate physical exercise. The beneficial effects of TCC on mental health were also observed in a study conducted by Kutner $e t a l^{\beta 3}$, in which confidence in balance, movement, and the motivation to participate in exercise were examined after a 15 week TCC intervention and a four month follow up. The study involved 200 elderly persons, who were randomly assigned to TCC exercise, computerised balance training, or education groups. A questionnaire was used to assess motivation to exercise and general sense of wellbeing. The results showed that both TCC and balance subjects reported increased confidence in balance and movement. In addition, they reported that their daily activities and overall life had been affected; many of these subjects had changed their normal physical activity to incorporate continuing TCC practice.

IMMUNE SYSTEM

A few studies have explored the impact of TCC exercise on immunological capacity. Zhang ${ }^{34}$ studied the effect of TCC on human serum immunoglobulin, IgA, IgG, IgM, and IgE after two months of TCC intervention. Thirty subjects aged 50-65 years, of whom 15 were men, participated in the study. They had no experience of TCC before joining the study. The intervention was designed to teach the 48 form TCC and allow one hour every day for practice. Blood analysis detected IgA, IgG, IgM, and IgE before and after the TCC training programme. It was found that the practice of TCC for two months significantly increased the level of IgG in men, and significantly decreased the level of $\operatorname{IgM}$ in women. These changes were all within the normal range, which indicated that TCC exercise may enhance the capacity of the immune system. $\mathrm{Li}$ and Shen ${ }^{35}$ studied changes in the number and activity of natural killer cells in peripheral blood after the practice of Wu TCC in eight male masters. The mean age of these subjects was 68.5 years, and they had practised for one to two hours every day for a mean of 19.2 years. They were asked to perform one set of Wu TCC which took about 20 minutes. Blood samples were taken two hours later, and the numbers and activity of natural killer cells in the peripheral blood had significantly increased. Moreover, this study found a concomitant increase in the level of cortisone in the blood. These results indicate that TCC exercise may moderate the capacity of the immune system in elderly people. However, more experimental evidence is needed to support these findings.

\section{Prevention of falls}

Falls are a significant public health problem, and the American National Safety Council ${ }^{36}$ suggests that they are the main cause of accidental death in the elderly. Falls and the resultant fractures lead to an increase in the expenditure on chronic disease and disability. Poor balance capacity, decreased muscle strength and flexibility, and the changes in gait that come with ageing are some of the risk factors associated with falls. ${ }^{36}{ }^{37}$ TCC exercise emphasises continuous slow movement, with small to large expressions of motion, unilateral to bilateral shifts of body weight, the progressive flexion of the knees, and rotation of the trunk, head, and extremities. These movement components seem to help to reduce the risk factors of falling. A longitudinal study of 28 TCC practitioners and 25 non-practitioners with a two year follow up showed that the regular practice of TCC could reduce the loss of bone mass density in the elderly. ${ }^{38}$ Furthermore, a study conducted by Wolfson et $a l^{1}$, with a relatively large sample size, provided important scientific evidence that TCC exercise could actually help to reduce falls. Wolf et $a l^{18}$ examined the effects of intervention with TCC exercise or computerised balance training on improving frailty and reducing falls in elderly people. They used physical, functional, behavioural, and environmental measures, an education group as the control for the study, and compared the specific biomedical changes among the three groups. Yang 108 form TCC was simplified to 10 forms for the TCC training. Each intervention lasted 15 weeks, with hour sessions for the education and balance training groups, while the TCC group met for two hour sessions but with a total instructional time equivalent to the other groups. All subjects were followed up for four months after the 15 weeks of intervention. The results showed that TCC training reduced the number of falls by $47.5 \%$, significantly attenuated the fear of falling, and improved physiological and psychosocial measures.

The changes in gait that come with ageing are also thought to be a factor related to falls in the elderly. A preliminary study of the impacts of TCC exercise on gait in older people has been reported by Wolf and Gregor. ${ }^{39}$ They examined the gait of 15 people from each of 20 independent living facilities. Each group either experienced 60-90 minutes of TCC exercise classes twice a week for 48 weeks or received information on wellbeing behaviour for one hour a week over the same period. Three of the 15 volunteers from each facility were evaluated for strength, and their gait was analysed every four months for 2 years. All subjects were 
tested for baseline measures at the start of the project, three times during the first year (during the TCC or wellbeing classes) and three times during the second year. Total body kinematics, lower extremity kinetics, and centre of pressure during gait initiation were calculated. The investigators studied normal walking at preferred speeds and situations during normal walking in which the subject had to move unexpectedly to the right in the step cycle and had to make unexpected turns beginning with either the right or left foot. The exemplar data indicated that individual strategies were apparent during each of these movements, and that each subject displayed a unique movement signature during both walking and turning. Thus was established a scientific basis for analysing the beneficial effects of TCC exercise on the prevention of falls in the elderly. However, the authors did not report the findings from their study.

Exercise is a significant intervention for preventing falls and fall related injuries. If falls occur at least in part because of physical deficits in balance, strength, reaction time, and flexibility, then it is plausible to believe that exercise targeted to improve these deficits may result in fewer falls or other injury events. In fact, many observational studies have shown an association between low levels of some types of physical function or activity and increased risk of falls and some types of injuries. ${ }^{41-43}$ Some authors have suggested that, of the physical deficits that appear with ageing in such areas as balance, strength, flexibility, and reaction time, balance deficits could be more directly responsible for falls than deficits in other areas. ${ }^{44}$ It could also be that elderly people are more aware of their strength, flexibility, and endurance limitations than they are of balance problems. There are many signs that can warn an elderly person of any decline in strength, flexibility, and endurance-for example, the inability to lift or reach while sitting or lying down and the like. Both the cross sectional and longitudinal studies of TCC have shown the effect of such exercise on improving physical deficits, particularly in balance capacity. ${ }^{14} 1618$ TCC exercise should be replete with dynamic balance training components. TCC practitioners have to exercise control, adjust their posture, and maintain their balance during shifts in the body's centre of gravity from unilateral and bilateral at a smooth and slow movement speed. Movement during the performance of TCC is characterised as the transformation of open and closed kinetic chain movements. The semisquatting posture used in the performance of TCC allows practitioners to control their centre of gravity and remain very stable. Thus, the characteristics of TCC exercise may train the proprioception of the practitioners. Posture control during the practice of TCC forces the muscles involved in movement to work hard, which may lead to increased muscle strength. Moreover, it has been suggested that the practice of TCC may increase the repertoire of motor programs stored in the brain and therefore serve to train the various balance systems to promote greater steadiness. ${ }^{14}$ However, the mechanism for improving balance capacity, and subsequently preventing falls, is still unclear. Experimental evidence on the characteristics of movement kinematics and kinetics and neuromuscular activity in TCC exercise has yet to be found. Further investigation is required into the scientific basis of the way in which TCC exercise improves the physical deficits experienced due to ageing.

\section{Summary}

TCC is a time honoured form of exercise that is recognised as being beneficial for men and women over a wide age range. Studies have shown that it can be classified as moderate exercise, as its intensity does not exceed $55 \%$ of maximal oxygen intake. The experimental evidence obtained from both cross sectional and longitudinal studies suggests that TCC exercise has beneficial effects on cardiorespiratory and musculoskeletal function, posture control capacity, and the reduction of falls experienced by the elderly. This applies to both healthy people and patients with chronic cardiovascular diseases, rheumatoid arthritis, or osteoarthritis. Considering these effects, TCC exercise has great potential for health promotion and rehabilitation, particularly for the maintenance of good mental and physical condition in the elderly. However, the effects of TCC exercise on other age groups should be further examined with well controlled experimental design studies.

In the literature there is a dearth of biomechanical studies. Some characteristics of muscular activity and movement kinematics and kinetics during the performance of TCC are understood, but how they help to improve movement capacity has not yet been explained. Solving this puzzle should provide a significant challenge to scientists of both medical and biomechanical disciplines.

The mind-body interaction is emphasised during TCC performance. Further studies that explore the effect of TCC exercise on mental control and on the musculoskeletal, nervous, and immune systems and their relations may provide more information on this unique exercise approach. TCC exercise may then be applied as physical and mental treatment for the rehabilitation of patients with cancer and other major health problems, as well as for the general maintenance of health.

The work described was substantially supported by a grant from the Research Grant Council of the Hong Kong Special Adminthe Research Grant Council of the Hong Kong Spe
istration Region (Project No CUHK4360/00H).

1 Mark BS. Combined tai chi chuan. Boston: Chinese Wushu Research Institute, 1979

$2 \mathrm{Yu}, \mathrm{Z}$. The third milestone of Tai Chi Chuan development. In: Hao X, ed. Chinese Wushu and traditional culture. Beijing: Beijing University of Physical Education Press, 1990;136-41.

3 Gong L, Qian J, Zhang J, et al. Changes in heart rate and electrocardiogram during Taijiquan exercise. Chin Med f (Engl) 1981;94:589-92.

4 Koh TC. Tai Chi Chuan. Am f Chin Med 1981;9:15-22.

5 Koh TC. Tai Chi and ankylosing spondylitis: a personal experience. Am f Chin Med 1982;10:59-61.

6 Xu S, Fan Z. Physiological studies of Tai Ji Quan in China. In: Qu M, Yu C, eds. China's sports medicine. Basel, New In: Qu M, Yu C, eds. China's
York: Karger, 1988:70-80. 
7 Chen WH, Zhao FS. The energy expenditure and the changes of micro-circulation in nails during practising $\mathrm{Ta}$ Chi Chuan. Fournal of Shanghai Institute of Physical Education 1984;8:1-7.

8 Zhuo D, Shephard RJ, Plyley MJ, et al. Cardiorespiratory and metabolic responses during Tai Chi Chuan exercise. Can $\mathcal{F}$ Appl Sport Sci 1984;9:7-10.

9 Brown DD, Mucci WG, Hetzler RK, et al. Cardiovascular and ventilatory responses during formalised Tai Chi Chuan exercise. Res Q Exerc Sport 1989;60:246-50.

10 Schneider D, Leung R. Metabolic and cardiorespiratory responses to the performance of Wing Chun and Tai Chi Chuan exercise. Int $\mathcal{F}$ Sports Med 1991;12:319-23.

$11 \mathrm{Cao}$ WY. The energy expenditure during practising Tai Chi Chuan. Exploring the science in Wu Shu. Beijing, China: People Sports Publishing House, 1990:234-43.

12 Lai JS, Lan C, Wong M, et al. Two-year trends in cardiorespiratory function among older Tai Chi Chuan practitioners piratory function among older Tai Chi Chuan practitioners

13 Liu Y, Yang B, Bai X. Effects of continuously performing 24 -form Taijiquan exercise one to three on cardiovascular
function of old people. Fournal of Beijing University of Physifunction of old people. Fourn

14 Tse SK, Bailey DM. Tai Chi and postural control in well elderly. Am f Occup Ther 1992;46:295-300.

15 Lan C, Lai JS, Wong MK, et al. Cardiorespiratory function, flexibility, and body composition among geriatric Tai Chi Chuan practitioners. Arch Phys Med Rehabil 1996;77: 612-16.

16 Hong Y, Li JX, Robinson PD. Balance control, flexibility, and cardiorespiratory fitness among older Tai Chi practitioners. Br $\mathcal{F}$ Sports Med 2000;34:29-34.

17 Schaller KJ. Tai Chi Chuan: an exercise option for older adults. F Gerontol Nurs 1996;22:12-17.

18 Wolf SL, Barnhart HX, Kutner NG, et al. Reducing frailty and falls in older persons: an investigation of Tai Chi and computerised balance training. Atlanta FICSIT Group. Frailty and Injuries: Cooperative Studies of Intervention Techniques. I Am Geriatr Soc 1996;44:489-97.

19 Techniques. F Am Geriatr Soc 1996;44:489-97. Chi Chuan training on balance, kinaesthetic sense, and Chi Chuan training on balance, kinaesthe

20 Shih J. Basic Beijing twenty-four form of Thai Chi exercise and average velocity of sway. Percept Mot Skills 1997;84 $287-90$

21 Wolfson L, Whipple R, Derby C, et al. Balance and strength training in older adults: intervention gains and Tai Ch maintenance. F Am Geriatr Soc 1996;44:498-506.

22 Lumsden DB, Baccala A, Martire J. Tai Chi for osteoarthritis: an introduction for primary care physicians. Geriatrics 1998;53:84-8.

23 Van Deusen J, Harlowe D. The efficacy of the ROM Dance Program for adults with rheumatoid arthritis. Am f Occup Ther 1987;41:90-5.

24 Kirsteins AE, Dietz F, Hwang SM. Evaluating the safety and potential use of a weight-bearing exercise, Tai-Chi Chuan, for rheumatoid arthritis patients. Am 7 Phys Med Rehabil 1991;70:136-41.

25 Beijing Medical University Institute of Sports Medicine (BMUISM). A medical observation on aged Tai Ji Quan players. Fournal of Beijing Medical University 1959;1:73100
26 Qu MY. Taijiquan: a medical assessment. In: Chinese Sports Editorial Board, ed. Simplified Taijiquan. Beijing: China Editorial Board, ed. Simplified Taijiquan. Beijing:

27 Lai JS, Wong MK, Lan C, et al. Cardiorespiratory responses of Tai Chi Chuan practitioners and sedentary subjects during cycle ergometry. F Formos Med Assoc 1993;92:894-9.

28 Zhang L. The effects of Tai Chi Chuan as exercise prescription on the changes of heomodynamics pre and post PWC $_{130}$ in the elderly. Chinese fournal of Sports Medicine 1994;13:167-70.

29 Channer KS, Barrow D, Barrow R, et al. Changes in haemodynamic parameters following Tai Chi Chuan and aerobic exercise in patients recovering from acute myocardial infarction. Postgrad Med F 1996;72:349-51.

30 Lan C, Chen SY, Lai JS, et al. The effect of Tai Chi on cardiorespiratory function in patients with coronary artery bypass surgery. Med Sci Sports Exerc 1999;31:634-8.

31 Jin P. Changes in heart rate, noradrenaline, cortisol and mood during Tai Chi. $\mathcal{F}$ Psychosom Res 1989;33:197-206.

32 Jin P. Efficacy of Tai Chi, brisk walking, meditation, and reading in reducing mental and emotional stress. $\mathcal{F}$ Psychosom Res 1992;36:361-70.

33 Kutner NG, Barnhart H, Wolf SL, et al. Self-report benefits of Tai Chi practice by older adults. F Gerontol 1997;52: 242-6.

34 Zhang GD. The impacts of 48 -form Tai Chi Chuan and Yi Qi Yang Fei Gong on the serum levels of IgG, IgM, IgA, and IgE in human. Fournal of Beijing Institute of Physical Education 1990;4:12-14

$35 \mathrm{Li} \mathrm{ZQ}$, Shen Q. The impact of the performance of Wu's Tai Chi Chuan on the activity of natural killer cells in peripheral blood in the elderly. Chinese fournal of Sports Medicine 1995;14:53-6.

36 National Safety Council. National safety council accidental facts. Chicago: National Safety Council, 1988.

37 Nickens $H$. Intrinsic factors in falling among the elderly. Arch Intern Med 1985;145:1089-93.

38 Perry B. Falls among the elderly: a review of the methods and conclusions of epidemiologic studies. F Am Geriatr Soc 982;30:367-71.

39 Wolf SL, Gregor RJ. Exploring unique applications of kinetic analysis to movement in older adults. I Appl Biomech 1999;15:75-83.

40 Young DR, Appel LJ, Jee S, et al. The effects of aerobic exercise and T'ai Chi on blood pressure in older people: results of a randomised trial. I Am Geriatr Soc 1999;47: $277-84$

41 Blake AJ, Morgan J, Bendall MJ, et al. Falls by elderly persons at home: prevalence and associated factors. Age Ageing 1988; 17:365-72.

42 Robbins AS, Rubenstein LZ, Josephson KR, et al. Predictors of falls among elderly people: results of two population-based studies Arch Intern Med 1989;149. 1628-33.

43 Lord SR, Clark RD, Webster IW. Postural stability and associated factors in a population of aged persons. $\mathcal{F}$ Gerontol 1991;46:M69-76.

44 Province MA, Hadley EC, Hornbrook MC, et al. The effects of exercise on falls in elderly patients. A preplanned meta-analysis of the FICSIT Trials. Frailty and Injuries: Cooperative Studies of Intervention Techniques. $7 A M A$ 1995;273:1341-7.

\section{Take home message}

A review of scientific studies published in both Chinese and English indicates that TCC can be classified as moderate exercise, as its intensity does not exceed $55 \%$ of maximal oxygen intake. The experimental evidence obtained from both cross sectional and longitudinal studies suggests that TCC exercise has beneficial effects on cardiorespiratory and musculoskeletal function, posture control capacity, and the reduction of falls experienced by the elderly. Further studies should explore the mechanism by which Tai Chi helps to improve movement capacity, and whether this form of exercise affects mental control. 